\title{
Review Article \\ Blast Protection of Unreinforced Masonry Walls: A State-of-the-Art Review
}

\author{
Lucas Lantz, Joshua Maynez, Wesley Cook, and Claudia Mara Dias Wilson \\ Civil and Environmental Engineering Department, New Mexico Institute of Mining and Technology, 801 Leroy Pl.,
} Socorro, NM 87801, USA

Correspondence should be addressed to Claudia Mara Dias Wilson; cwilson@nmt.edu

Received 23 April 2016; Revised 2 August 2016; Accepted 16 August 2016

Academic Editor: Chiara Bedon

Copyright (C) 2016 Lucas Lantz et al. This is an open access article distributed under the Creative Commons Attribution License, which permits unrestricted use, distribution, and reproduction in any medium, provided the original work is properly cited.

\begin{abstract}
The recent rise of terrorist attacks has reinforced the need for mitigation of damage caused by blast loading on unreinforced masonry walls. The primary goal of the techniques is to prevent the loss of life while simultaneously preserving the integrity of the structure. This paper presents a compilation of recently available literature on blast protection of unreinforced masonry walls. It seeks to present the state of the art in this field, including mitigation techniques considered as well as testing methods selected. Fiber reinforced polymers and polyurea are the two dominant retrofitting techniques being assessed in the field. Other techniques include but are not limited to polyurethane, steel sheets, and aluminum foam. Since there is no widely implemented standard for blast loading test procedures, direct comparisons between the efficiencies of the mitigation techniques proposed are not always feasible. Although fragmentation is an indicator of the efficiency of retrofits, it is currently measured by subjective observation of postblast debris.
\end{abstract}

\section{Introduction}

Recurring individual terrorist attacks and accidental explosive incidents can be cited in the western world such as Texas (2005), London (2005), Connecticut (2010), and Boston (2013) as a reason for a push in blast resistant research of civilian structures. In 2010 alone, there were 13,186 terrorist attacks worldwide [1]. Generally, terroristic acts attempt to cause the most amount of physical and psychological damage to the people present and to the populace as a whole while accidental explosions can undermine the safety of nearby occupants. Therefore, most retrofitting and design techniques aim to diminish the effectiveness of attacks by reducing injury and loss of life or improving safety for occupants. Fragmentation of elements in or as part of a structure is considered "hazardous" by ASCE 51-11 [2] and is assigned the lowest level of performance. Since fragmentation is generally the most deadly part of a blast event [3], aside from building collapse, it is often a key part of the analysis when judging the effectiveness of a retrofit technique. Finding the most costeffective method to reduce the fragmentation of buildings could be a benefactor for both the industrialized and the developing parts of the globe.
Due to the recent rise of terrorist attacks globally, the purpose of this research is to inform engineers and scientists of the current design and retrofit techniques available for unreinforced masonry. This paper will address the types of retrofitting techniques for unreinforced masonry walls currently being researched in roughly the last 15 years. Buchan and Chen [4] and Malvar et al. [5] conducted stateof-the-art reviews in 2007 related to the topic and most reviewed investigations herein were published at a later date. Reinforced masonry is less susceptible to fragmentation and as a result this study focuses on unreinforced masonry.

This paper reviews the materials investigated, experimental components, numerical simulations, and fragmentation mitigation.

\section{Materials Descriptions}

A search of the literature in the past 15 years showed that the most prevalent types of retrofitting techniques for unreinforced masonry walls include fiber reinforced polymers and polyurea, with polyurethane, steel sheets, aluminum foam, and engineering cementitious composites all being investigated as well. An overview of these techniques is presented in the following. 
2.1. Fiber Reinforced Polymers. Fiber reinforced polymers (FRP) are composite unidirectional fabrics in a matrix which are attached to the surface of the masonry wall usually with epoxy or resin. The fibers add strength to the wall by preventing out-of-plane bending and shear. FRP increases the strength and ductility of the structure while limiting the amount of flying debris. Several different studies have addressed the use of FRP for blast protection of masonry walls in the past 15 years $[6-8,13-19]$. Derivatives to FRP are carbon fiber reinforced polymer (CFRP) and glass fiber reinforced polymer (GFRP).

2.2. Polyurea. Polyurea is an elastomer commonly used in a variety of applications for its water, abrasion, and chemical resistance. Polyurea appears to be an effective retrofitting technique because it usually reduces the fragmentation of the masonry wall $[9,10,12,14,20-22]$. Generally, researchers chose to apply it as a spray-on material to the interior face of the wall. As of 2016, more recent studies appear to favor finite element estimations or comparisons of the wall's reaction. Polyurea's performance can be adjusted by the use of certain additives [21].

2.3. Polyurethane. Polyurethane is a material that is similar chemically to polyurea, but it comes in a variety of different forms such as a spray-on adhesive and a thin film. Recently, little has been done to evaluate its effectiveness as a retrofit technique.

2.4. Steel Sheets. Steel sheets are another potential retrofitting technique for masonry walls. However, steel sheets are laborious to install, add substantial dead load to the wall, and significantly increase cost [4]. For these reasons, FRP sheets and aluminum foam sheets are considered more attractive alternatives.

2.5. Aluminum Foam. Aluminum foam is a lightweight solid material retaining a lot of aluminum's original properties such as corrosion resistance and strength. Aluminum foam is a promising retrofit material because of its early onset of plastic deformation which allows it to dissipate blast load energy [23].

2.6. Engineered Cementitious Composites. Engineering cementitious composites (ECC) are mixtures of typical concrete ingredients in addition to a small amount of fiber. ECC has good strength and ductility characteristics in addition to high fracture toughness. Variations of ECC have shown the ability to absorb high energy impacts [22]. These characteristics have made ECC a possible candidate for increasing masonry's resistance to blast loading.

\section{Experimental Investigations}

3.1. Fiber Reinforced Polymers. Urgessa and Maji [13] conducted a study with eight masonry walls. Four of the eight walls were reinforced with an inorganic matrix containing a liquid potassium silicate solution and an amorphous silica powder. Two of the walls had two layers and the other two
TABLE 1: Approximate deflections [6].

\begin{tabular}{lc}
\hline Wall & Displacement $(\mathrm{mm})$ \\
\hline CM1R & 0.8 \\
CM1L & 0.8 \\
CM3L & 0.8 \\
CM4R & 1.2 \\
CM4L & 1.2 \\
CM5R & 1.8 \\
CM5L & 0.5 \\
CM6R & 1.0 \\
CM6L & 1.1 \\
\hline
\end{tabular}

had four layers. The remaining four walls were reinforced with a thixotropic epoxy resin and a $2: 1$ hardener. Both mixes were applied to the walls as FRP sheets. Again, two walls had two layers and two walls had four layers. Each of the eight walls was subject to a blast load of $0.45 \mathrm{~kg}$ booster which is equivalent to $0.64 \mathrm{~kg}$ TNT. The walls were set up in a circle around the blast source with a radius of $1.83 \mathrm{~m}$. The walls with two layers experienced displacement ranging from 14.5 to $18.8 \mathrm{~cm}$. Large horizontal cracks formed along most of the mortar joints. The walls with four layers experienced displacement of $10.0 \mathrm{~cm}$ to $12.9 \mathrm{~cm}$. No visible cracks were seen and fragmentation was contained in all tests.

Tan and Patoary [6] applied a 20.92 GJ (5-ton TNT) blast to three masonry walls and a $112.97 \mathrm{GJ}$ (27-ton TNT) blast to three additional masonry walls. Walls subject to a $112.97 \mathrm{GJ}$ blast were anchored to the ground surface and walls subject to the $20.92 \mathrm{GJ}$ blast were not anchored. Each of these tests was performed three times for a total of eighteen masonry walls. The distances of the test are shown in Figure 1. Each set of walls was assigned a module number in the form of "CM" followed by the wall number. Additionally, "R" and "L" are added to the end to denote which of the walls was being addressed. For example, CM1R refers to the first wall set and the right wall in that particular set. The varying use of carbon FRP, glass FRP, woven roving, and stiffeners can be seen in Figure 1 and the approximate results based on the graphs presented by Tan and Patoary [6] can be seen in Figure 1 and Table 1, respectively.

Some of the walls were designed to experience plastic deformation. However, each of the walls tested showed no visible signs of cracking or delamination and each wall was considered successful. Based on the results presented in Table 1, it can be inferred that glass FRP and woven roving had similar effectiveness.

Baylot et al. [14] conducted a 1/4-scale model of a $1 \mathrm{~mm}$ thick glass FRP attached to the back face of a masonry wall. The wall was subject to varying magnitude and distances of the charge. Though the wall became detached from the frame and experienced mortar joint cracking, the wall was still considered a success because the wall remained intact and upright. This particular experiment was unique in that it measured the effectiveness of the retrofit by reading the velocity of the flying debris. Though the FRP did aid in limiting the amount of debris, this method of comparing 

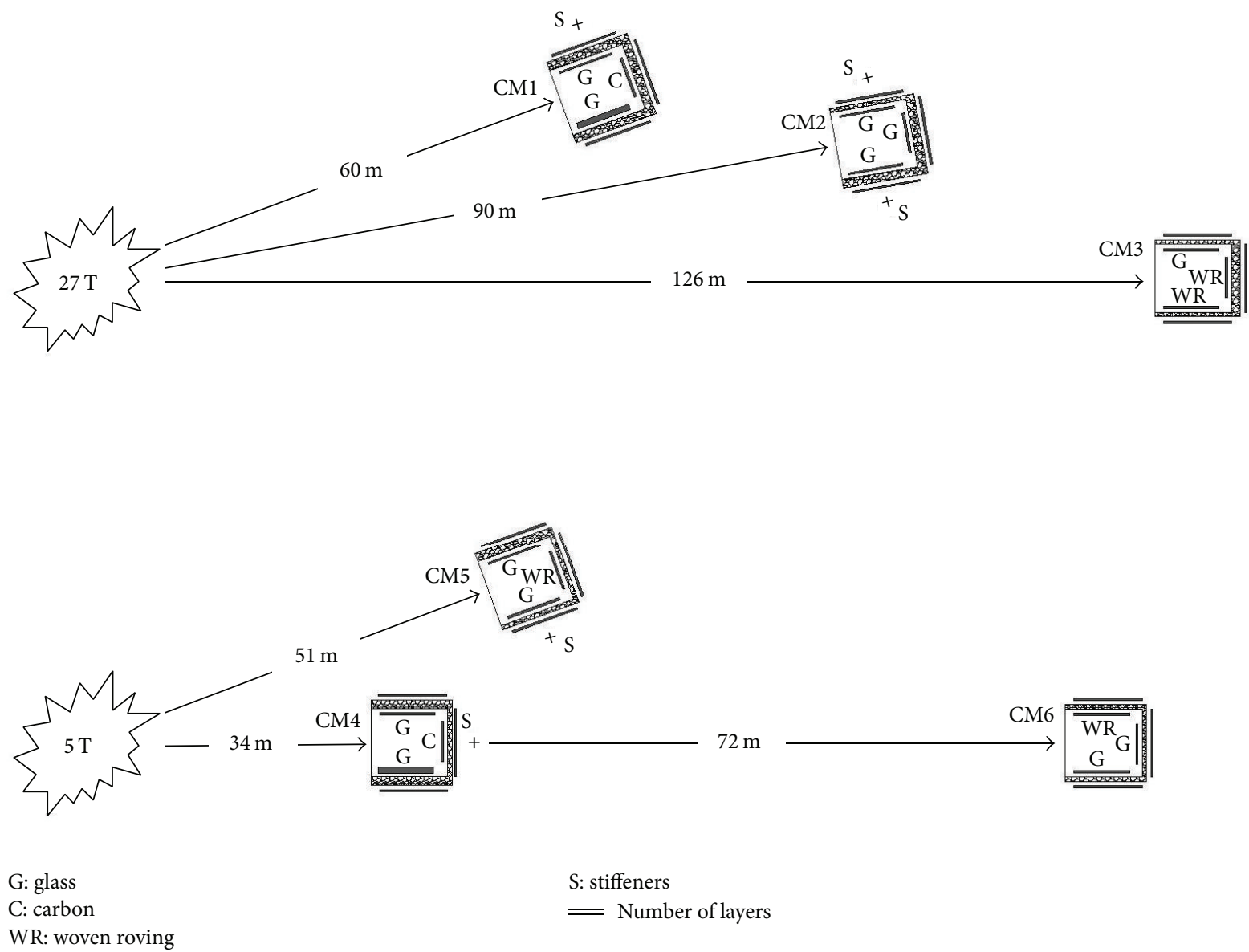

Figure 1: Tan and Patoary's [6] test setup.

the velocities was not as effective at indicating the degree of hazard as was originally assumed.

Stanley et al. [7] used two-part spray-on polyurea along with aramid FRP. This test was successful, containing all of the debris. The maximum deflection of the wall was approximately $230 \mathrm{~mm}$. As seen in Figures 2(a) and 2(b), the left wall was the control and had no retrofitting. The wall to the right was the wall reinforced with polyurea and aramid FRP.

Stratford et al. [15] attached glass FRP sheets to clay brick walls and concrete masonry unit walls. The sheets were applied in both the horizontal and the vertical directions to increase the shear strength of the wall. The walls were subject to a prestressed load of $100 \mathrm{kN}$ in the vertical (compressive) direction. The horizontal load was increased in $50 \mathrm{kN}$ increments. The maximum load applied to the clay brick wall and concrete unit wall was $195 \mathrm{kN}$ and $130 \mathrm{kN}$, respectively.

The corresponding maximum deflections were $1.4 \mathrm{~cm}$ and $1.3 \mathrm{~cm}$. Both walls displayed rapid cracking under the load along the mortar joints. Debonding of the fabric from the wall also occurred at some locations along the walls.
Alsayed et al. [16] used $200 \times 200 \times 400 \mathrm{~mm}$ hollow concrete masonry units to construct walls within a $2.1 \mathrm{~m}$ long by $1.5 \mathrm{~m}$ high reinforced concrete frame. Six masonry walls were included in the experimental procedures, three of which were reinforced with $1.85 \mathrm{~mm}$ thick GFRP sheets placed in orthogonal directions. The other three walls were unreinforced. The tests included three different sized charges placed at different distances from the wall: $1.134 \mathrm{~kg}, 4.8 \mathrm{~m}$; $49.9 \mathrm{~kg}, 4.8 \mathrm{~m}$; and $14.2 \mathrm{~kg}, 2.0 \mathrm{~m}$, respectively. Each test used one unreinforced masonry wall and one GFRP reinforced wall. All charges were set off at a height of $0.75 \mathrm{~m}$ above the ground. To judge the effectiveness of the retrofit, Alsayed et al. [16] used Department of Defense Minimum Antiterrorism Standards for Buildings' four levels of damage [3]. Both of the walls affected by the $1.134 \mathrm{~kg}$ blast showed no damage and were given a protection rating of high. For the $49.9 \mathrm{~kg}$ blast, both walls were given a protection rating of medium but showed different types of damage. The unreinforced wall had light damage with blocks pushed out along with minor detachment at the wall-frame interface. The reinforced wall showed debonding at both the wall-frame interface and the 


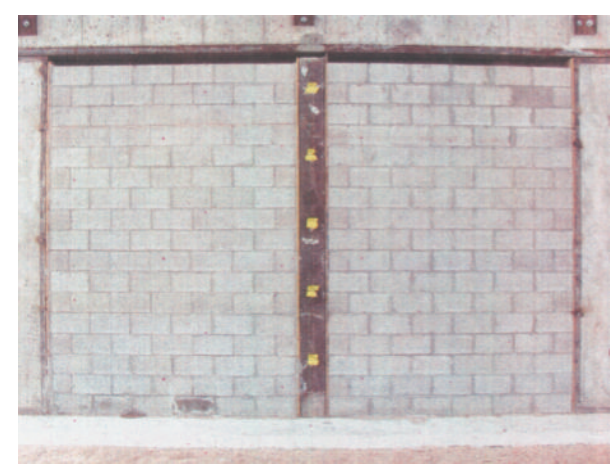

(a)

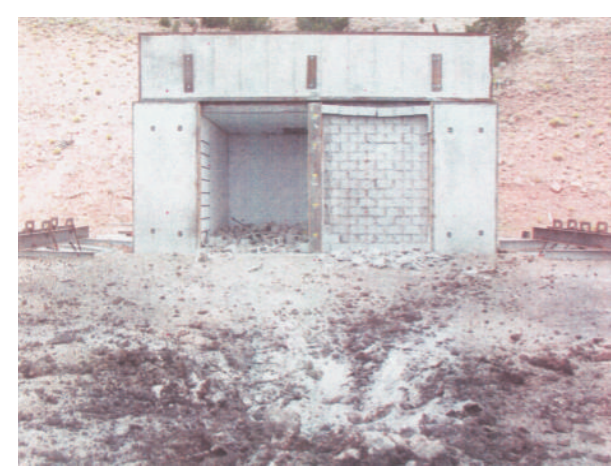

(b)

FIGURE 2: Stanley et al.s [7] blast test (a) before blast test and (b) after blast test.

FRP-frame interface. For the $14.2 \mathrm{~kg}$ charge, both walls failed but were graded differently because the GFRP reinforced wall prevented flying debris. The unreinforced wall was given a protection level of very low and the reinforced wall was given a protection level of low. GFRP reinforced masonry walls were concluded to show potential as a retrofit technique and were considered to be effective in preventing fragmentation.

Bui and Limam [17] considered two-way bending of unreinforced masonry due to vertical loads and lateral loads (pressures) for which blast loading can be conjectured. The experiments used hollow concrete blocks sized $20 \times 20 \times$ $50 \mathrm{~cm}$ to construct the four test wall setups. From the top view, three walls form to make a $U$ with only straight lines. The bottom of the $U$ is the main wall: it is $2.9 \mathrm{~m}$ long and $2.0 \mathrm{~m}$ tall. The adjacent side walls are $1.0 \mathrm{~m}$ long and $2.0 \mathrm{~m}$ tall. Two different types of foundation were used for the walls. Wall 1's foundation slab was U-shape dimensioned at $310 \times$ $120 \times 20 \mathrm{~cm}$ while Walls $2-4$ had a rectangular slab sized $350 \times 185 \times 25 \mathrm{~cm}$. Walls 3 and 4 were retrofitted with a CFRP composite but the amount of CFRP was different. Wall 3 used 7 vertical CFRP strips and 6 horizontal CFRP strips that were $20 \mathrm{~mm}$ wide and $2 \mathrm{~m}$ long. Wall 4's strips were only $7.5 \mathrm{~mm}$ wide. The static pressure on the wall was increased until the displacement of the wall reached $50 \mathrm{~mm}$. The CFRP reinforced walls had noticeable increases in bearing capacity. Wall 4 reached a capacity of $90 \mathrm{kN} / \mathrm{m}^{2}$ and Wall 3 reached a capacity of $140 \mathrm{kN} / \mathrm{m}^{2}$ in comparison to unreinforced Wall 2's capacity of $58 \mathrm{kN} / \mathrm{m}^{2}$. Wall stiffness was analyzed as the slope of the pressure displacement curve. When the curve became nonlinear, it signaled the development of cracks and their growth. The CFRP improved the walls stiffness and prevented cracks from developing. Walls 1, 2, and 4 had similar main wall crack patterns: vertical cracks in the center of the wall and diagonal cracks forming from the lower corner of the main wall. Wall 3, however, only had small cracks on the main wall. Wall 4 and Wall 3 saw cracks on the adjacent walls because of the flexural bending in the main wall. Bui and Limam [17] concluded that together the walls show that simply supported walls perform better than walls with real boundary conditions and more research under realistic boundary conditions must be conducted in order to properly evaluate the effectiveness of the CFRP retrofit.
Chen et al. [18] conducted 6.5-scale blasting tests on $1.5 \mathrm{~m}$ high $\times 2 \mathrm{~m}$ wide $\times 0.2 \mathrm{~m}$ thick walls. MU15 $\mathrm{P}$ type porous bricks sized $90 \mathrm{~mm}$ width $\times 90 \mathrm{~mm}$ height $\times 190 \mathrm{~mm}$ length were used to construct the walls. The TNT charge size used on the walls ranged from 0.2 to $34.2 \mathrm{~kg}$. The scaled standoff distance ranged from 1.81 to $10 \mathrm{~m} / \mathrm{kg}^{1 / 3}$. Three types of retrofit material were examined in blast tests: CFRP, steel wire mesh, and steel bars. CFRP strips with a thickness of $1.2 \mathrm{~mm}$ and a width of $30 \mathrm{~mm}$ were bonded with an epoxy adhesive to the back of the wall in the horizontal and vertical directions. Steel wire mesh was attached to the back of the masonry wall with nails followed by a $10 \mathrm{~mm}$ layer of plastered mortar. Steel bars with a $2 \mathrm{~mm}$ thickness and $30 \mathrm{~mm}$ width were bonded with nails and epoxy adhesive on the back side of the wall. Eight pressure gauges were arranged on the front of the masonry to record measurements. All three retrofitting techniques improved the performance of the wall. Under $3.9 \mathrm{~kg}$, unreinforced masonry walls saw residual displacement of about $3 \mathrm{~mm}$ at the center of the wall while the CFRP, steel wire mesh, and steel bar reinforced walls saw $1 \mathrm{~mm}$ or less of displacement. Likewise, the retrofitting techniques had about $3 \mathrm{~mm}$ of maximum displacement, in comparison to the $6 \mathrm{~mm}$ of maximum displacement in the unreinforced walls. Chen et al. [18] noted that the effectiveness of the retrofitting techniques increased with higher charge weights. The CFRP strip retrofitting reduced the residual displacement the most out of any of the retrofitting techniques, reducing displacement by $92 \%$. In comparison, the steel mesh reduced the residual displacement by $67 \%$. Under visual inspection, the walls told a reverse story other than the displacement. The CFRP retrofitted walls had some shear rupture delamination while the steel mesh only had little spallation of the concrete. While all retrofitting materials were able to reduce the scattering of fragments, it was clear that the CFRP and steel bar retrofitting techniques were more damaged than the steel mesh. The steel mesh was therefore concluded to be the most efficient retrofitting technique.

Hamed and Rabinovitch [19] used $400 \times 200 \times 200 \mathrm{~mm}$ concrete masonry units to construct 2 masonry walls $1230 \mathrm{~mm}$ wide by $2100 \mathrm{~mm}$ tall. Walls were enclosed in a $1.5 \mathrm{~m}$ by $2.5 \mathrm{~m}$ steel frame and rested upon a reinforced concrete base beam. CFRP was chosen as the retrofit material. The 

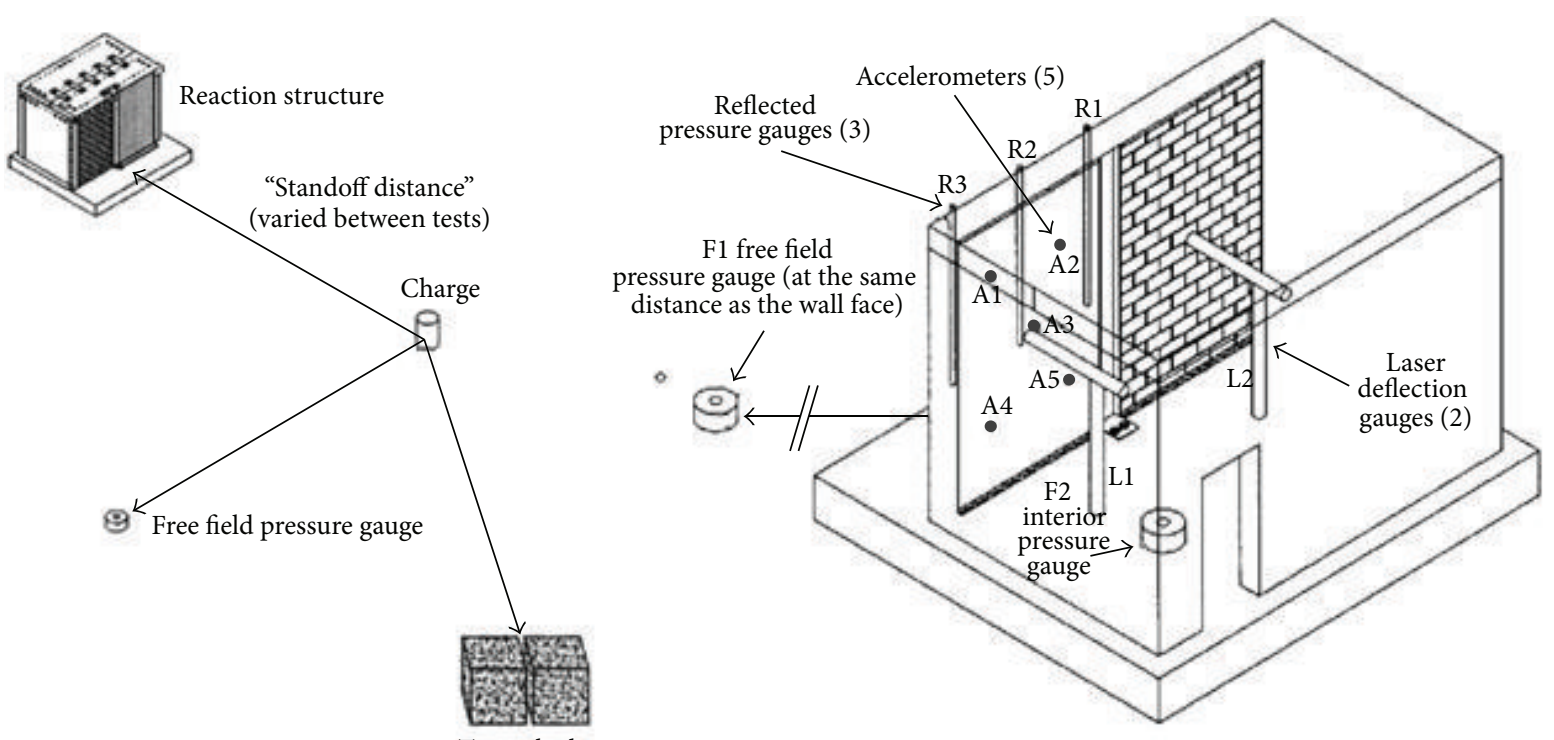

Figure 3: Full-scale masonry wall test setup $[8,9]$.

CFRP strips applied to the wall were $50 \mathrm{~mm}$ wide and $1.2 \mathrm{~mm}$ thick. CFRP was attached to the walls by applying $3 \mathrm{~mm}$ of epoxy to the wall and $2 \mathrm{~mm}$ of epoxy to the CFRP strips. The epoxy sides were then attached to each other and allowed to cure for 10 days. The loads applied were two out-of-plane knife-edge loads created by $300 \mathrm{kN}$ hydraulic jack. One wall was a control wall with no reinforcement and the other was reinforced with CFRP. The CFRP wall failed at 1.25 times the load of the unreinforced wall. The behavior of the CFRP and unreinforced wall was different leading up to failure. The unreinforced wall showed a nonlinear behavior in regard to a load-deflection curve while the CFRP reinforced wall did show a linear behavior up to failure. Likewise, the CFRP reinforced wall had $1 / 3$ of the deformation at the point of failure compared with the control wall. The unreinforced wall failed suddenly and was classified as a total collapse failure. The sudden collapse of the unreinforced wall could have been because of the crushing of the masonry units, a shear failure, or both but could not be pinpointed by Hamed and Rabinovitch [19]. Likewise, the cause of failure for the reinforced wall was also hard to determine. Hamed and Rabinovitch [19] gave two possible reasons: debonding of the free edges of the CFRP and shear failure of the masonry units. Although the CFRP did increase the strength of the wall, Hamed and Rabinovitch [19] noted that the increase was smaller than that in other literature, most likely because of the more realistic supporting conditions.

3.2. Polyurea. Davidson et al. [8] judged 21 different polymers that included seven thermoplastic sheets, one brush-on polymer, and 13 spray-on polymers. Out of all the materials, pure polyurea spray-on materials were chosen for their strength, cost, stiffness, ductility, and resistance to fire. This first test had three masonry walls, two of which had polyurea applied only to the interior side of the wall, and the other had polyurea applied to both sides. The size of the charge was not reported due to sensitivity of the subject. When the treated walls were compared to their unreinforced control counterpart, all of the retrofitted walls appeared to be able to reduce fragmentation well. It is noted that this is most likely due to the polyurea's ability to absorb strain energy, bond to the surrounding structure, and bond to the wall itself. These tests also showed that the walls' mechanism of failure was affected by the support conditions, peak pressure, and duration.

Davidson et al.s [9] follow-up study addresses complications encountered in the earlier tests. Twelve walls with varying dimensions in the range $2.4 \mathrm{~m}-3.7 \mathrm{~m} \times 2.3 \mathrm{~m}-4.9 \mathrm{~m}$ were subjected to explosive loads. The test setup is seen in Figure 3. Similar to Davidson et al.s [8] study, polyurea systematically increased the resistance of the walls to blast loading but some specific behavioral mechanisms were noted on the polyurea walls: (1) stress waves traveled throughout the wall and caused fracture, (2) the direct impact of the blast load caused some immediate fracture, (3) tearing of the polyurea coating occurred near the supports, (4) the front face of the wall suffered fracture due to flexure, (5) the polyurea reinforcement tore under flexure, and (6) the system collapsed when the polyurea tore or lost its adhesive properties to the exterior structure. Individual masonry blocks were placed at different distances and were subjected to the same blast. Notably, a change in distance of roughly 61 centimeters caused notable changes in the blocks ability to resist the blast.

Johnson et al. [20] conducted a study involving two sets of masonry walls in evaluation. The first set of full-scale walls used three different retrofitting techniques, all of which used polyurea as part of the reinforcement. The first used spray-on polyurea in combination with aramid fabric, the second used trowel on polyurea alone, and the third used trowel on polyurea as an adhesive for thermoplastic film. 


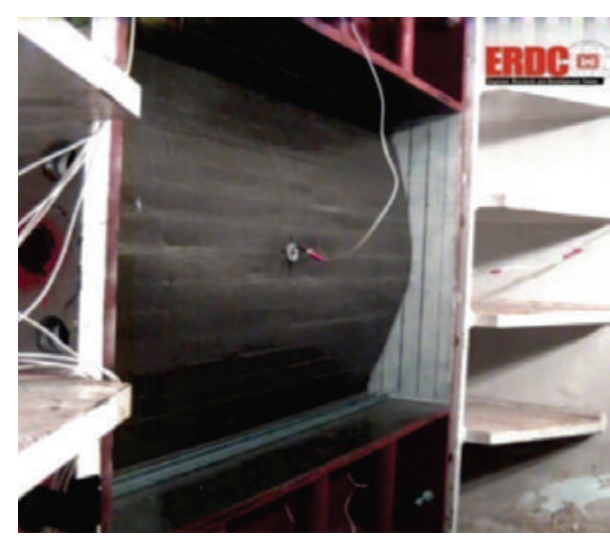

(a)

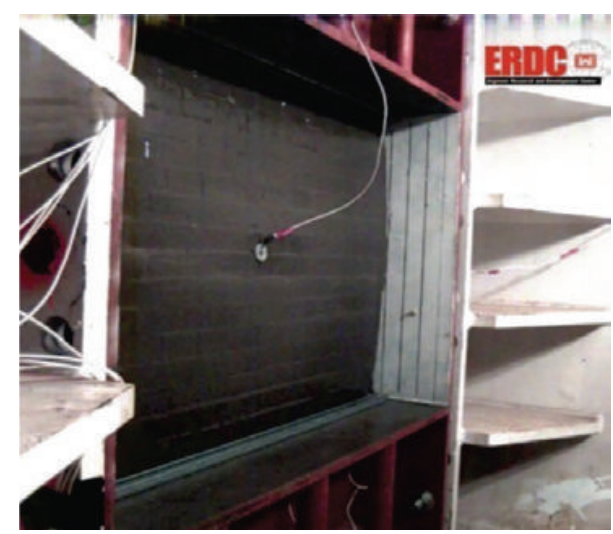

(b)

FIGURE 4: POSS-reinforced wall (a) at maximum deflection and (b) in the final stage [10, 11].

Only dynamic tests were done on full-scale walls. The other set of walls was scaled down by a quarter and had seven different types of retrofit systems applied. This set of walls was evaluated using both scaled static and dynamic tests. Of the seven types, one used spray-on polyurea as the primary retrofitting technique, one used trowel on polyurea with aramid fabrics as additional reinforcement, three more used spray-on polyurea in combination with the aramid fabrics, and the other two did not use polyurea. Johnson et al. [20] had a few main conclusions from the test. First, the static load tests closely resemble the dynamic results for quarterscaled masonry walls. Also, the quarter-scaled masonry walls performed similarly to the full-scale walls, implying that using scaled masonry walls to judge the effectiveness of a fullscale wall is acceptable. Every type of retrofitting technique appeared to reduce the amount of debris during loading. The unreinforced retrofit systems increased ultimate flexural resistance in comparison to nonretrofitted walls by a factor of 1.9 to 4.0 , while the aramid reinforced system increased the ultimate flexural resistance by a factor of 5.5 to 7.5 . This implies that using the polyurea in combination with the aramid fabric was the most effective retrofitting technique in terms of ultimate flexural resistance.

Baylot et al. [14] also did 1/4-scale tests using spray-on polyurea. The polyurea was applied to the interior face of the masonry walls at a thickness of $3.2 \mathrm{~mm}$. As previously stated, walls were subject to varying magnitude and distances of the charge in order to get the desired level of peak pressure and impulse. The polyurea was successful at keeping the majority of the debris (interpreted as fragmentation) out of the structure during the blast event. Therefore, polyurea was considered a successful retrofitting technique because it reduced the hazard behind the masonry wall.

Irshidat et al. [10] compared three different polyurea mixes. One is an unreinforced standard polyurea, one is reinforced with exfoliated graphene nanoplatelets (XGnP), and the other is reinforced with polyhedral oligomeric silsesquioxane (POSS). The test used scaled down masonry blocks sized $54 \times 57 \times 115 \mathrm{~mm}$. The wall was 16 blocks high and 12 blocks long. The U.S. Army Engineer Research and Development Center's blast simulator was used to perform dynamic tests on each of the wall types. The unreinforced polyurea wall experienced a tensile failure at a blast peak pressure of $208.22 \mathrm{kPa}$. The XGnp-reinforced wall had a primary horizontal crack form at the peak pressure of $224.91 \mathrm{kPa}$. The crack caused the wall to split into two pieces and collapse. The POSS retrofitted wall had shear damage and horizontal cracks at its peak pressure of $218.91 \mathrm{kPa}$. Conclusions were primarily based on isodamage pressure-impulse curves that encompassed all of the tests. Although Irshidat et al. [10] specifically noted that XGnp-reinforced wall's retrofitting system was effective at reducing fragmentation in the blast and the POSS retrofitted wall can be seen to have no fragments in it (Figure 4), Irshidat et al. [10] concluded by saying that fragmentation was not addressed. This is most likely because the blast simulator, like static or other tests, does not cause the same amount of fragmentation on impact as a real explosive.

Wang et al. [12] performed explosive tests on 6 walls, 4 of which were constructed out of $24 \times 11.5 \times 5.3 \mathrm{~cm}$ clay bricks. The other 2 were constructed out of $20 \times 20 \times 60 \mathrm{~cm}$ aerated concrete blocks. Clay walls were $3.6 \mathrm{~m}$ wide by $2.8 \mathrm{~m}$ tall and the concrete walls were $2.4 \mathrm{~m}$ wide by $2.2 \mathrm{~m}$ tall. Two gauges were used to measure the peak pressure and impulse due to the blasts on the wall. The first gauge was placed at the center of the wall and the second was placed at a distance of one-fifth of the walls width away from the first gauge. Some of the key statistics are included in Table 2. Note that the burst height for every test was $1.4 \mathrm{~m}$ and the standoff is the distance between the charge and the wall. In general, the polyurea retrofitted walls appeared to perform much better than the retrofitted walls. Wang et al. [12] concluded that this was because (a) initial cracking occurred before collapse; (b) the impact force in the reinforced wall was 18 times higher in the aerated brick and 4 times higher in the clay brick; (c) the face of the walls did not fracture. The failure modes were different between the reinforced clay brick walls and the aerated masonry walls. The unreinforced clay masonry wall 
TABLE 2: Failure criteria [12].

\begin{tabular}{|c|c|c|c|c|}
\hline $\begin{array}{l}\text { Test charge weight } \\
(\mathrm{kg})\end{array}$ & Charge size (kg) & Standoff $(\mathrm{m})$ & $\begin{array}{l}\text { Thickness } \\
(\mathrm{mm})\end{array}$ & Failure criteria \\
\hline Test 1: Y2 & 2 & 1 & 0 & $\begin{array}{l}\text { Control wall severely collapsed above burst height without front face } \\
\text { fracture. }\end{array}$ \\
\hline Test 2: TQ-Z-J-D-5 & 5 & 1.0 & 3 (partially) & $\begin{array}{l}\text { Wide crack propagated completely the thickness of the wall with large } \\
\text { deformation. The polyurea layer is intact with some tensile strain } \\
\text { marks. }\end{array}$ \\
\hline Test 3: TQ-Z-J-2-4 & 8 & 1.0 & 3 (fully) & $\begin{array}{c}\text { The initial crack occurred at the center of the top without } \\
\text { deformation. }\end{array}$ \\
\hline Test 4: TQ-Z-J-1 & 20 & 1.0 & 3 (fully) & $\begin{array}{l}\text { The wall rotated about bottom and severely collapsed due to overload. } \\
\text { Polyurea was torn and separated completely from the front face. }\end{array}$ \\
\hline Test 5: TQ-Q-W-2 & 5 & 10 & 0 & $\begin{array}{l}\text { The wall presented mortar joint separation and would reach the } \\
\text { critical state of collapse due to large deformation. }\end{array}$ \\
\hline Test 6: TQ-Q-J-2 & 5 & 3.0 & 3 (fully) & $\begin{array}{l}\text { The wall underwent large deformation with side parts warping and } \\
\text { disengaging from columns. There was no tearing of the polyurea. }\end{array}$ \\
\hline
\end{tabular}

failed because of the separation of brick and mortar joint. However, in the reinforced clay masonry wall, vertical and diagonal cracks eventually spread throughout the entire wall.

The aerated masonry walls failed due to mortar joint separation because of the low strength of the mortar brick connection in the aerated masonry wall. Fracture was not observed on the front face of the clay brick masonry walls but was found in the aerated masonry walls. The reinforced walls of both kinds were observed to have successfully contained the debris of the blast. Fully reinforced clay masonry walls had 4.5 to 11 times the blast resistance of the unreinforced clay masonry walls. Fully reinforced aerated masonry walls had 15 times the blast resistance of the unreinforced aerated masonry walls. Clay masonry walls, reinforced or unreinforced, performed much better overall at resisting the blasts than their aerated counterparts.

3.3. Polyurethane. Knox et al. [21] performed tests on both standalone polyurethane and polyurea/polyurethane mixes. All of the polymers in the study were noted to increase ductility and decrease wall fragmentation. In later studies, pure polyurea was used because of strength, flammability, and cost $[4,21]$. The most recent study to experiment with pure polyurethane was that of Johnson et al. [20], where polyurethane film was applied to an unreinforced masonry wall with a tape and epoxy system. The polyurethane increased the ultimate flexural strength of the wall, but its ability to reduce fragmentation was not gathered because it was not used in the dynamic tests.

3.4. Steel Plates. Recent investigations of steel plates and unreinforced masonry are rare due to the noted challenges of cost and increased dead load [9].

3.5. Aluminum Foam. Experimental blast loading to aluminum foam and unreinforced masonry is an area of potential research.

3.6. Engineered Cementitious Composites. Maalej et al. [22] created 18 clay brick walls that have a $1000 \times 1000 \mathrm{~mm}$ face and are $100 \mathrm{~mm}$ thick. The solid clay bricks used to build the wall were $215 \times 100 \times 70 \mathrm{~mm}$. The walls were divided into three series of 6 walls. In series 1 and 2 , there were two control unreinforced walls while series 3 had just 1 unreinforced wall. Each series contained one reinforced wall with the following configurations: (a) a single-faced $34 \mathrm{~mm}$ thick engineering cementitious composite (ECC) layer, (b) a double-faced $34 \mathrm{~mm}$ thick ECC layer, (c) a single-faced $34 \mathrm{~mm}$ thick ECC layer with $8 \mathrm{~mm}$ diameter steel mesh, and (d) a double-faced $34 \mathrm{~mm}$ thick ECC layer with $8 \mathrm{~mm}$ diameter steel mesh. The ECC used in this study was a hybrid-fiber mix containing $1.5 \%$ of high performance polyethylene and $0.5 \%$ of steel fibers. The first and second series of walls were subjected to a quasi-static load test while the third was subjected to lowvelocity impact load testing. The quasi-static load tests differ in that the first series load was applied on a $100 \times 100 \mathrm{~mm}$ patch of the wall while the second series had a $780 \times 780 \mathrm{~mm}$ distributed load applied. The quasi-static tests showed that the ECC retrofitting techniques, in general, were able to increase the ultimate capacity of the walls. Series 1 walls showed an increase in the failure loads by 6.5 and an increase in deflection capacity by 17.3 in comparison to the base wall. Series 2 walls showed an increase in the failure loads by 6.5 and an increase in deflection capacity by 17.3 in comparison to the base wall. Under the impact loads, the damage level was assessed based on the average crater diameter, indentation depth, crack propagation, and fragmentation. Walls with steel mesh showed a decrease in crater size and indentation depth in comparison to walls without it. Likewise, double-sided walls also showed increased penetration resistance like their steel mesh counterparts. Maalej et al. concluded that this was because the ECC at the impact face was able to absorb a large amount of impact energy. The ECC strengthened masonry walls were concluded to be able to increase the masonry wall's resistance to impact loads.

\section{Numerical Simulations}

4.1. Fiber Reinforced Polymers. Ghaderi et al. [24] simulated, in ABAQUS, FRP strips $1.5 \mathrm{~mm}$ thick in a vertical, horizontal, 
and blended formation on the interior face of masonry walls, a blast loading model. The blast was measured by a scaled distance parameter, $Z$ :

$$
Z=\frac{R}{W^{1 / 3}},
$$

where $R$ is the distance at which the blast is applied and $W$ is the weight of the TNT. The scaled distance was unique to this study. The walls were subject to a scaled distance parameter of $2.2 \mathrm{~m} / \mathrm{kg}^{1 / 3}, 1.8 \mathrm{~m} / \mathrm{kg}^{1 / 3}$, and $1.5 \mathrm{~m} / \mathrm{kg}^{1 / 3}$. As the distance to the wall decreased, more cracks occurred and more fiber became detached from the wall. Fragmentation was not addressed explicitly by Ghaderi et al.; however, it can be inferred from the modeling that fragmentation would be minimized in the actual field.

Alsayed et al. [16] created a finite element model in ANSYS-AUTODYN to represent their $2.1 \mathrm{~m}$ long by $1.5 \mathrm{~m}$ high masonry wall surrounded by a reinforced concrete frame. The model contained four distinct Lagrangian parts: the RC frame, RC footing, infill masonry wall, and the GFRP sheets. The RC frame, RC footing, and infill masonry wall were all modeled as 8-node hexahedral elements while the GFRP sheets were 4-node shell elements. Air around the wall was modeled as an Euler ideal gas. Explosives were modeled using the Jones-Wilkins-Lee equation of state. Blast modeling was done with a two-step process involving a 1D radial analysis of the explosion followed by a $3 \mathrm{D}$ analysis used to judge the effect of the blast on masonry wall. 1D analysis was done until a reflecting surface is reached. The $1 \mathrm{D}$ analysis is then remapped within the $3 \mathrm{D}$ model. Alsayed et al. [16] set the model to terminate after $10 \mathrm{~ms}$ since it was considered enough time to investigate the effects of the blast. For each of the five tests, the charge size and standoff distance were $1.134 \mathrm{~kg}, 4.8 \mathrm{~m}, 49.9 \mathrm{~kg}, 4.8 \mathrm{~m}, 14.2 \mathrm{~kg}, 2.0 \mathrm{~m}$, $113.4 \mathrm{~kg}, 4.0 \mathrm{~m}$, and $500 \mathrm{~kg}, 4.0 \mathrm{~m}$, respectively. The FE model used was validated by comparing finite element analysis to ConWep values and to the experimental results of the studies. Alsayed et al. [16] found that the arrival time of the blast, peak incident, and peak reflected overpressures matched between the three and went on to conclude that the numerical solution was a valid way to analyze the FRP-strengthened walls and the unstrengthened walls.

LS-DYNA was employed by Chen et al. [18] to perform structural analysis on MU15 P type porous brick walls. CFRP, steel mesh, and steel bars were evaluated numerically to judge them as possible retrofitting and repairing techniques for masonry walls. The masonry and mortar were modeled as 8 -node solid elements. To model the steel mesh retrofit technique, a two-node Hughes-Liu beam element with $2 \times$ 2 Gauss quadrature integration was used. The steel bars and CFRP were represented as $22.5 \times 22.5 \mathrm{~mm}$ 3D shell elements. In regard to the material model parameter, Chen et al. [18] used Mat_72Rel3 that consisted of three failure surfaces: the initial yield surface, the maximum yield surface, and the residual yield surface. To model the steel and FRP, material models 24 and 54 were used, respectively. Modeling the epoxy adhesive is key to capturing an experimentally confirmed failure mode in LS-DYNA, which is the delamination of the FRP sheets from the masonry wall. Chen et al. [18] used the
Automatic Surface-to-Surface Tiebreak to model the contact of the masonry wall and FRP to the epoxy. Walls were also modeled to be on top of a concrete slab as in the experimental tests. The anchors holding the wall down were modeled using tied node sets with failure using the Contact Tiebreak Node to Surface option. Numerical results were found to be similar to the experimental results performed by Chen et al. [18]. Both the steel bars and the CFRP were almost completely delaminated from the wall, but CFRP performed better by having less fragmentation. The steel mesh retrofitted walls were able to prevent all serious damage. The main form of damage on the steel mesh walls was the spallation of plastered mortar.

Hamed and Rabinovitch [25] presented a theoretical numerical model to properly describe the behavior of FRP-strengthened masonry walls subjected to out-of-plane loads. Numerous equations and conditions are presented to describe some of the behavioral conditions of the masonry walls, including bonding conditions and equilibrium equations. Using the mathematical descriptions, a step-by-step process is presented to find a solution regarding the masonry wall's rigidity. First, an initial guess is made; in this case, the mortar joints of the masonry wall are assumed to be uncracked. Second, using the rigidities derived in the initial guess to allow for the solving of the governing equations, an analysis of the structure is performed. Once an analysis of the structure has been performed, an analysis of the mortar joints is performed as follows: the strain distribution is found with step two's solution, the depth of the active zone in the cracked joint, and then the rigidity of each joint. Lastly, the steps are repeated until the difference between the original rigidity and the calculated rigidity is reasonably small. The numerical model was then used to compare the distribution of internal forces and deflection between an unreinforced masonry wall and one modeled with FRP strips. FRP strips notably had concentrations of shear and tensile stress near joint edges. Hamed and Rabinovitch [25] noted that this coincided well with the debonding failure mechanisms in other papers' experimental studies. Likewise, Hamed and Rabinovitch [25] stated that stiffer FRP tended to increase out-of-plane deflection, internal shear, and axial forces on the masonry walls and FRP strips in their numerical study.

Hamed and Rabinovitch [19] adjusted their previous mathematical model (Hamed and Rabinovitch [25]) to properly describe the nonlinear behavior of materials subjected to failure level loads. Six critical failure mechanisms of the strengthened masonry walls were examined in the numerical analysis. They are as follows: crushing of the masonry units, shear failure of masonry units, rupture of the composite material, debonding of the strengthening system, sliding/shear at the mortar joints, and crushing of the mortar joints. The model followed the same set of steps as Hamed and Rabinovitch [25]: an initial guess regarding the rigidity of the structure, an analysis of the structure, an analysis of the rigidity of the joints, and then convergence where the initial rigidity closely matches the calculated rigidity of the joints. The analytical results of the model agreed fairly well with the experimental tests performed, showing that the control wall's load capacity was about $25 \%$ less than that of the CFRP 
reinforced wall's load capacity. In this sense, the experimental model validated the analytical model to some degree and led Hamed and Rabinovitch [19] to use a nonlinear model to properly describe the behavior of mortar joint and its interfaces.

4.2. Polyurea. Ghaderi et al. [24], through simulation in ABAQUS, tested polyurea at a range of thicknesses from 5 to $15 \mathrm{~mm}$ when applied to both sides of the wall, at the scaled distance of $0.9 \mathrm{~m} / \mathrm{kg}^{1 / 3}$. Polyurea was then tested at a thickness of $15 \mathrm{~mm}$ when applied to one side of the wall as well. The impulse ratio for polyurea applied on the interior side of the wall was $859 \%$ and for polyurea applied on both sides was $1623 \%$. The means for each wall's maximum impulse were 8.59 and 16.23 times higher, respectively, than an unreinforced wall. Polyurea was concluded to be an effective retrofit technique that has high performance capabilities and is effective at reducing fragmentation. Double-sided carbon FRP had the highest FRP impulse ratio at 465\%. Therefore, polyurea performed considerably better than even the most effective FRP method in regard to impulse ratio.

Aghdamy et al. [11] also evaluated the effectiveness of XGnP- and POSS-reinforced polyurea on the same walls Irshidat et al. [10] used. A finite element model was created to compare the physical and computer test results, although it was in LS-DYNA. However, the XGnP-reinforced polyurea performed worse when compared to the unreinforced polyurea according to Aghdamy et al's [11] analysis and was concluded to have less blast resistance than both the POSS-reinforced polyurea and the unreinforced polyurea. Based on their impulse-pressure diagrams, Aghdamy et al. [11] were able to conclude that the POSS-reinforced polyurea was the most effective polyurea tested at resisting high pressures under short durations, but all polyurea types were effective in low pressure, long duration events.

Irshidat et al. [10] also created a finite element model with ANSYS-AUTODYN. The finite element model was considerably accurate in its ability to estimate the effects of the test loading with regard to debris velocity, midpoint deflection, and the walls' failure mechanisms. In combination, the tests showed that the POSS-reinforced polyurea had noteworthy improvement over the unreinforced polyurea, while the XGnP-reinforced polyurea showed little to no improvement of the unreinforced polyurea.

Along with the physical tests, Davidson et al. [8] used LS-DYNA3D to improve the understanding of the behavior of the blast loading. The finite element model mostly agreed with the deflection and accelerometer gauges attached to the masonry walls during loading. Together, the tests showed that a thin layer of polyurea applied to the inner face of the wall significantly reduced fragmentation. Polyurea effectively bonded to the masonry, which demonstrates that it is a viable retrofit material. Finally, it was concluded that elongation capacity is more important than high stiffness for a blast retrofitting material.

4.3. Aluminum Foam. Su et al. [23] conducted a finite element analysis on aluminum foam using LS-DYNA. A series of numerical analyses were done with scaled $Z$ values (see (1)) on unreinforced masonry walls. The aluminum foam was $40 \mathrm{~mm}$ thick in the analysis and had a density of $400 \mathrm{~kg} / \mathrm{m}^{3}$. At $Z=4 \mathrm{~m} / \mathrm{kg}^{1 / 3}$, the unreinforced masonry wall was blown out immediately by the air-blast load, while the wall reinforced with aluminum foam at $Z=4 \mathrm{~m} / \mathrm{kg}^{1 / 3}$ appeared to only have light damage. The thickness of the aluminum foam was then tested at $12 \mathrm{~mm}$ and $24 \mathrm{~mm}$ for $Z=$ $3 \mathrm{~m} / \mathrm{kg}^{1 / 3}$. The results showed that the larger the thickness of the aluminum foam is, the better it was at mitigating the blast. Overall, the analysis showed aluminum foam to be a promising option for mitigating a blast.

Aghdamy et al. [11] also conducted finite element analyses on aluminum foam using LS-DYNA. Aghdamy et al. [11] modeled foam layers of varying thicknesses, $13 \mathrm{~mm}, 20 \mathrm{~mm}$, and $25 \mathrm{~mm}$, but constant density, $450 \mathrm{~kg} / \mathrm{m}^{3}$. Increasing the foam's thickness was found to be effective at increasing its resistance to blast load. Aluminum foam was then modeled on both sides of an unreinforced masonry wall at $13 \mathrm{~mm}$ thickness on both sides of the wall. An impulse-pressure diagram was created from this model. From the diagram, aluminum foam was concluded to be an effective retrofitting technique. POSS polyurea was also analyzed in the same way. It was applied to both sides of a wall at a thickness of $4.5 \mathrm{~mm}$. Aluminum foam, in comparison to the POSS polyurea, was more effective in the quasi-static regime while POSS polyurea was better at resisting loads in the dynamic and impulsive regime.

Su et al.s [23] and Aghdamy et al.s [11] finite element analyses show that aluminum foam has the potential to be a new material for resisting blast loading. This makes experimental tests of the material desirable.

\section{Fragmentation Mitigation}

There is no apparent method for determining the amount of fragmentation beyond subjective observation and comparison. Baylot et al. [14] hypothesized that debris velocity could be a viable measure of fragmentation but observations proved velocity to be a poor indicator. The Department of Defense Minimum Antiterrorism Standards for Buildings [3] has developed four levels of protection assessments which account for flying debris in the standard; however, these levels of protection typically were not used, or not reported on, in the various reviewed articles. Regardless, when flying debris is evident, the lowest level of performance is assigned. Thus, fragmentation is a binary response (it either did or did not occur), without regard to the amount or reduction based on treatments. In addition to fragmentation, blast loading and standoff distance varied by the level of performance and with each investigation. Thus, fragmentation mitigation efforts must rely on comparisons conduction within the respective investigations.

5.1. Fiber Reinforced Polymers. FRP is the most widely used material to investigate the performance on unreinforced masonry walls. It has shown good success in both numerical and experimental investigation at reducing the amount of fragmentation during blast events. FRP is an effective method at reducing the amount of fragmentation. In addition, FRP 
can increase shear wall ductility and improve structural integrity through collapse prevention.

5.2. Polyurea. Davidson et al. [8] selected pure polyurea spray-on material out of 21 different polymers based on strength, cost, stiffness, ductility, and resistance to fire. From this and from subsequent investigators, polyurea exhibited the most promise to mitigate fragmentation with comparative advantages over other retrofitting materials.

5.3. Polyurethane. Polyurethane was noted to have the ability to reduce fragmentation as well as polyurea and FRP. Knox et al. [21] performed tests on both standalone polyurethane and polyurea/polyurethane mixes, both of which performed well and successfully decreased wall fragmentation. However, polyurethane's ability to reduce fragmentation has not recently been evaluated. Likewise, the type of polyurethane used has the potential to alter its effectiveness.

5.4. Steel Plates. Steel plates have the unique advantage compared to other retrofitting techniques of being a wellknown, highly controlled, and predictable material. In addition, construction industry laborers have existing knowledge of steel for installation purposes. Steel is ductile and dense providing excellent protection against fragmentation and spalling of masonry due to blast loading. However, due to the dead load increases, it is best suited for single story buildings in retrofit applications.

5.5. Aluminum Foam. Aluminum foam has yet to be experimentally tested but it shows a high potential to resist blast loading, limits fragmentation, and has a limited increase to the dead load of a structure.

5.6. Engineered Cementitious Composites. ECC were subjected to low-velocity (nonblast) type loadings. ECC are anticipated to have good performance against fragmentation but have yet to be experimentally tested. These composites show promise with the desirable qualities of increased strength, durability, and energy dispersion for retrofitting unreinforced masonry. Regardless, these materials can provide secondary masonry elements such as return walls and interior walls with the ability to contain damage due to blast loads.

5.7. Recommendation. For future investigations analysis relating to the level of protection found in the Department of Defense Minimum Antiterrorism Standards for Buildings [3] or similar standard would provide more comparative data universally.

\section{Conclusions}

Retrofitting techniques for blast protection of unreinforced masonry walls such as FRP, polyurea, polyurethane, steel sheets, and aluminum foam have been presented in this paper. These techniques have been investigated over the last 15 years to enhance the strength and ductility of unreinforced masonry walls and decrease fragmentation. However, it is difficult to compare test results and methods since there is no publically set standard for the magnitude of blasts or the distance at which the blast is applied. General findings of the different retrofitting materials include the following:

(1) FRP and polyurea are the two most widely studied retrofitting techniques because of their effectiveness, lightweight, practicality of application, and cost.

(2) Fragmentation is a key indicator of the effectiveness [13] of the mitigation techniques employed as binary response flying debris or no flying debris.

(3) Elongation capacity is more important than high stiffness for a blast retrofitting material [8].

(4) Results from experimental tests show that glass FRP and woven roving have similar effectiveness [6].

(5) Direct FEA comparison of FRP retrofitting techniques to polyurea retrofitting techniques showed that interior polyhedral oligomeric silsesquioxane polyurea retrofit had higher impulse ratio of $859 \%$ when compared to double-sided carbon FRP's 464\% [24].

(6) Aluminum foam was more effective in the quasistatic test than polyhedral oligomeric silsesquioxane polyurea, while the polyhedral oligomeric silsesquioxane polyurea was more effective in the dynamic and impulsive tests [11].

(7) Boundary conditions affect the performance of masonry walls subjected to lateral loads. Simulating realistic boundary conditions allows for more accurate interpretation of a retrofitting technique's performance [17].

\section{Competing Interests}

The authors declare that they have no competing interests.

\section{References}

[1] M. Nagdy and M. Roser, “Terrorism," 2016, http://ourworldindata.org/terrorism/.

[2] American Society of Civil Engineers (ASCE), "Blast protection of buildings," ASCE/SEI 59-11, 2011.

[3] DoD, "DoD minimum antiterrorism standards for buildings," Tech. Rep. UFC 4-010-01, US Department of Defense (DoD), 2013.

[4] P. A. Buchan and J. F. Chen, "Blast resistance of FRP composites and polymer strengthened concrete and masonry structures-a state-of-the-art review," Composites Part B: Engineering, vol. 38, no. 5-6, pp. 509-522, 2007.

[5] L. J. Malvar, J. E. Crawford, and K. B. Morrill, "Use of composites to resist blast," Journal of Composites for Construction, vol. 11, no. 6, pp. 601-610, 2007.

[6] K. H. Tan and M. K. H. Patoary, "Blast resistance of FRPstrengthened masonry walls. I: approximate analysis and field explosion tests," Journal of Composites for Construction, vol. 13, no. 5, pp. 422-430, 2009.

[7] M. Stanley, J. Metzger, and R. Martinez, "UL-like testing of commercial off-the-shelf products that enhance the blast and 
ballistic resistance of structures, quick look report 2," Tech. Rep. TR-04-48, 2005.

[8] J. S. Davidson, J. R. Porter, R. J. Dinan, M. I. Hammons, and J. D. Connell, "Explosive testing of polymer retrofit masonry walls," Journal of Performance of Constructed Facilities, vol. 18, no. 2, pp. 100-106, 2004.

[9] J. S. Davidson, J. W. Fisher, M. I. Mammons, J. R. Porter, and R. J. Dinan, "Failure mechanisms of polymer-reinforced concrete masonry walls subjected to blast," Journal of Structural Engineering, vol. 131, no. 8, pp. 1194-1205, 2005.

[10] M. Irshidat, A. Al-Ostaz, A. H.-D. Cheng, and C. Mullen, "Nanoparticle reinforced polymer for blast protection of unreinforced masonry wall: laboratory blast load simulation and design models," Journal of Structural Engineering, vol. 137, no. 10, pp. 1193-1204, 2011.

[11] S. Aghdamy, C. Wu, and M. Griffith, "Simulation of retrofitted unreinforced concrete masonry unit walls under blast loading," International Journal of Protective Structures, vol. 4, no. 1, pp. 21-44, 2013.

[12] J. Wang, H. Ren, X. Wu, and C. Cai, "Blast response of polymerretrofitted masonry unit walls," Composites Part B: Engineering, 2016.

[13] G. S. Urgessa and A. K. Maji, "Dynamic response of retrofitted masonry walls for blast loading," Journal of Engineering Mechanics, vol. 136, no. 7, pp. 858-864, 2010.

[14] J. T. Baylot, B. Bullock, T. R. Slawson, and S. C. Woodson, "Blast response of lightly attached concrete masonry unit walls," Journal of Structural Engineering, vol. 131, no. 8, pp. 1186-1193, 2005.

[15] T. Stratford, G. Pascale, O. Manfroni, and B. Bonfiglioli, "Shear strengthening masonry panels with sheet glass-fiber reinforced polymer," Journal of Composites for Construction, vol. 8, no. 5, pp. 434-443, 2004.

[16] S. H. Alsayed, H. M. Elsanadedy, Z. M. Al-Zaheri, Y. A. AlSalloum, and H. Abbas, "Blast response of GFRP-strengthened infill masonry walls," Construction and Building Materials, vol. 115, pp. 438-451, 2016.

[17] T. T. Bui and A. Limam, "Out-of-plane behaviour of hollow concrete block masonry walls unstrengthened and strengthened with CFRP composite," Composites Part B: Engineering, vol. 67, pp. 527-542, 2014.

[18] L. Chen, Q. Fang, J. Fan, Y. Zhang, H. Hao, and J. Liu, "Responses of masonry infill walls retrofitted with CFRP, steel wire mesh and laminated bars to blast loadings," Advances in Structural Engineering, vol. 17, no. 6, pp. 817-836, 2014.

[19] E. Hamed and O. Rabinovitch, "Failure characteristics of FRPstrengthened masonry walls under out-of-plane loads," Engineering Structures, vol. 32, no. 8, pp. 2134-2145, 2010.

[20] C. F. Johnson, T. R. Slawson, T. K. Cummins, and J. L. Davis, "Concrete masonry unit walls retrofitted with elastomeric systems for blast loads," in Proceedings of the 24th Army Science Conference, Orlando, Fla, USA, 2004.

[21] K. J. Knox, M. I. Hammons, T. T. Lewis, and J. R. Porter, Polymer Materials for Structural Retrofit, Force Protection Branch, Air Expeditionary Force Technology Division, Air Force Research Laboratory, Tyndall Air Force Base, Fla, USA, 2000.

[22] M. Maalej, V. W. J. Lin, M. P. Nguyen, and S. T. Quek, "Engineered cementitious composites for effective strengthening of unreinforced masonry walls," Engineering Structures, vol. 32, no. 8, pp. 2432-2439, 2010.
[23] Y. Su, C. Wu, and M. Griffith, "Mitigation of blast effects on aluminum foam protected masonry walls," Transactions of Tianjin University, vol. 14, no. 1, pp. 558-562, 2008.

[24] M. Ghaderi, V. A. Maleki, and K. Andalibi, "Retrofitting of unreinforced masonry walls under blast loading by FRP and spray on polyurea," Cumhuriyet Science Journal, vol. 36, no. 4, pp. 462-477, 2015.

[25] E. Hamed and O. Rabinovitch, "Out-of-plane behavior of unreinforced masonry walls strengthened with FRP strips," Composites Science and Technology, vol. 67, no. 3-4, pp. 489-500, 2007. 


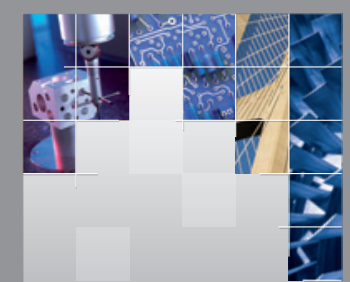

\section{Enfincering}
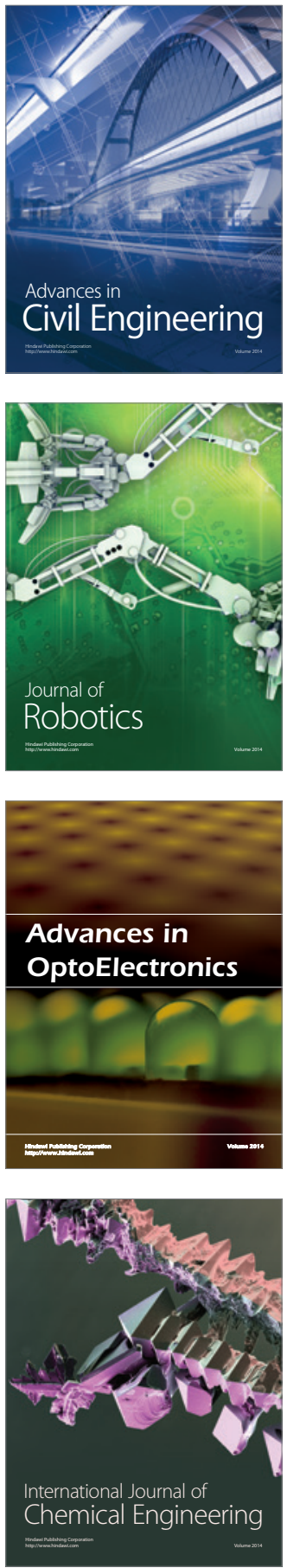

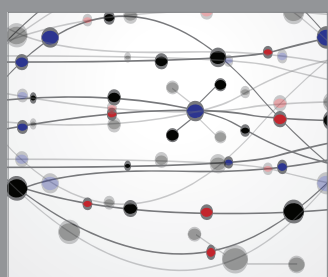

The Scientific World Journal

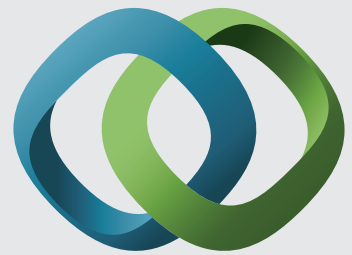

\section{Hindawi}

Submit your manuscripts at

http://www.hindawi.com
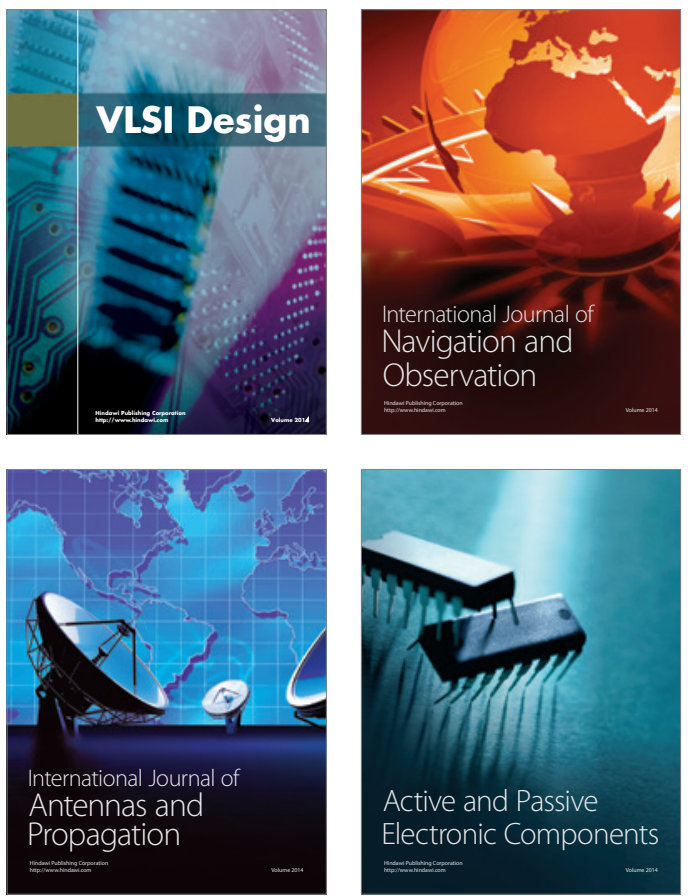
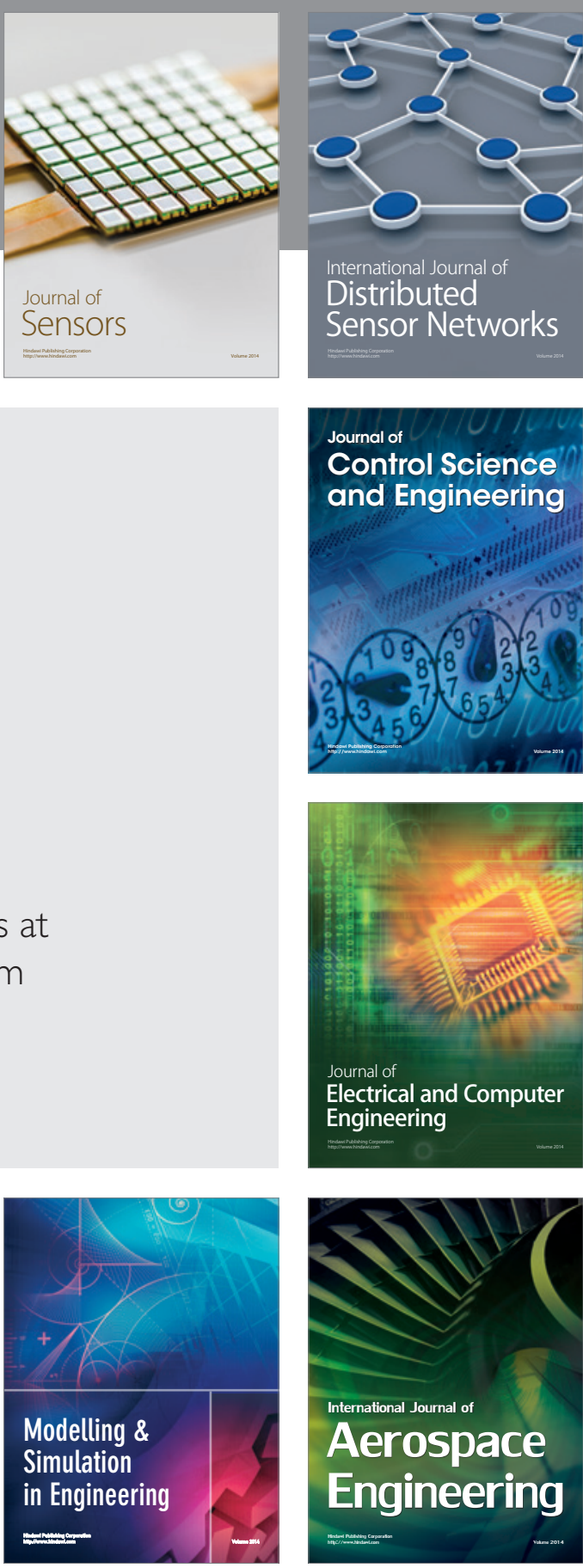

International Journal of

Distributed

Sensor Networks

Journal of

Control Science

and Engineering
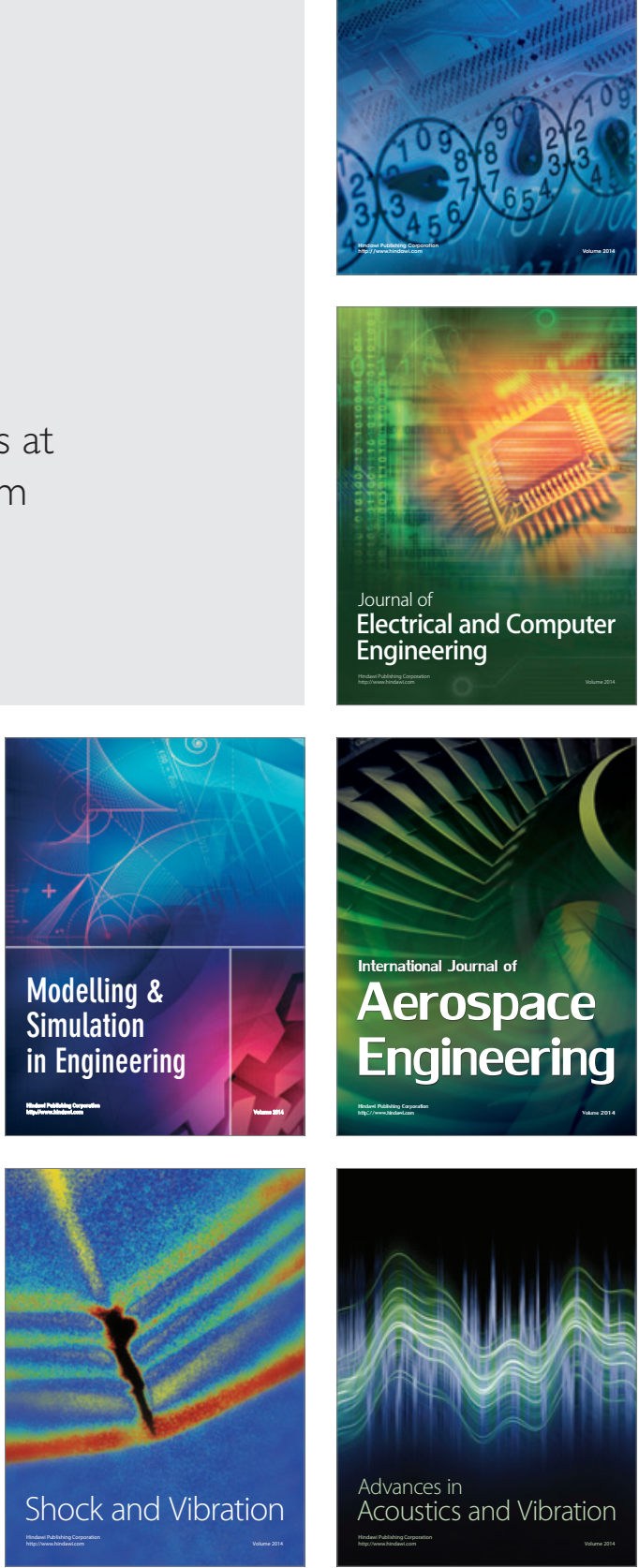